\title{
Percutaneous thoracolumbar decompression combined with percutaneous pedicle screw fixation and fusion: a method for treating spinal degenerative pain in a biplane angiography suite with the avoidance of general anesthesia
}

\author{
Bohdan W. Chopko \\ Department of Neurosurgery, Stanford University, NV, USA \\ Correspondence to: Bohdan W. Chopko, Ph.D, MD. Stanford -St. Rose Center for Neurosurgery, 2865 Siena Heights Dr., Suite 131, Henderson, NV \\ 89052, USA. Email: bchopko@stanford.edu.
}

\begin{abstract}
Background: Spondylytic degeneration of the axial lumbar spine is a major cause of pain and disability. Recent advances in spinal surgical instrumentation, including percutaneous access and fusion techniques, have made possible the performance of instrumented fusion through small incisions. By blending strategies of interventional pain management, neuroradiology, and conventional spine surgery, it is now feasible to treat spinal axial pain using permanent fixation techniques and local anesthesia in the setting of a fluoroscopy suite using mild sedation and local anesthesia.

Methods: The author presents a series of percutaneous thoracolumbar fusion procedures performed in a biplane neuroangiographic suite and without general anesthesia for the treatment of spondylytic pain. All procedures utilized pedicle screw fixation, harvesting of local bone autograft, and application of bone fusion material.

Results: In this series of 13 patients, a statistically significant reduction of pain was seen at both the 2-week post-operative timepoint, as well as at the time of longest follow-up (mean 40 weeks).

Discussion: The advanced and rapid imaging capabilities afforded by a neuroangiographic suite can be safely combined with percutaneous fusion techniques so as to allow for fusion therapies to be applied to patients where the avoidance of general anesthesia is desirable.
\end{abstract}

Keywords: Spondylosis; fusion; pedicle screw; sedation; biplane suite

Submitted Jun 07, 2016. Accepted for publication Jun 17, 2016.

doi: 10.21037 /jss.2016.06.03

View this article at: http://dx.doi.org/10.21037/jss.2016.06.03

\section{Introduction}

Spondylytic degeneration of the axial spine is a growing challenge with an incidence that increases with age. In addition to age-dependent deterioration, medical comorbidities also increase as the patient population ages, which in turn leads to greater reluctance on the part of surgeons to offer traditional open surgical procedures. Over the past decade, development of percutaneous fixation and fusion techniques, notably pedicle screwbased posterior instrumentation systems, have made posterior thoracolumbar spinal fusion procedures possible via relatively tiny incisions $(1,2)$. The percutaneous access of the pedicle, such as for vertebral biopsy or cement augmentation, is a routine procedure typically performed within a fluoroscopy suite using local anesthesia and sedation (3). Since percutaneous pedicle screw placement is essentially conceptually identical to vertebroplasty, it is a natural progression to envision the placement of pedicle screw fixation systems in the angiography suite environment.

The author describes his initial experience in performing percutaneous posterior thoracolumbar instrumented 

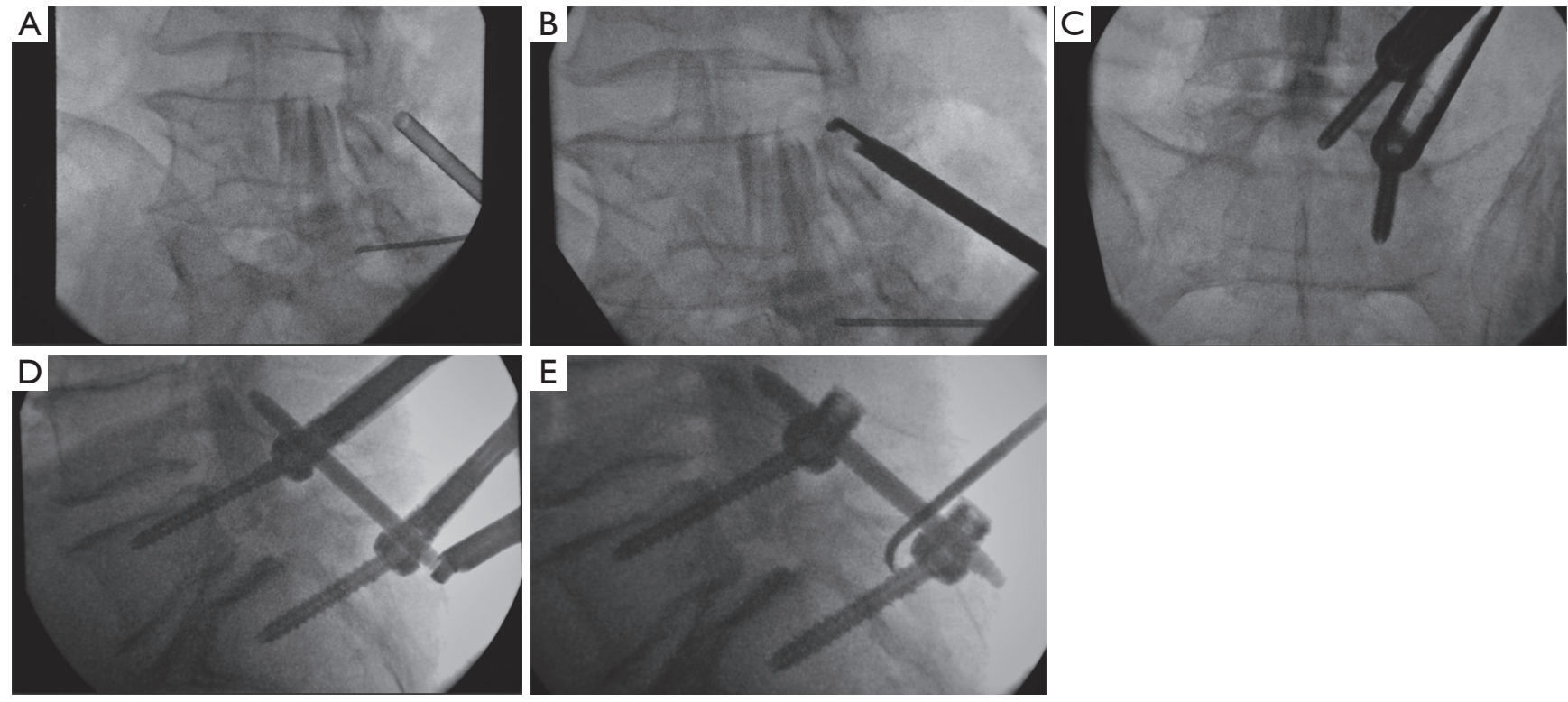

Figure 1 Work flow sequence as seen in fluoroscopic images. (A) Access cannula for mild decompression docked at the L5 laminar level, reverse oblique view. An epidural needle is present at S1 through which contrast has been injected to achieve an epidurogram; (B) bone sculptor in use to resect laminar edge and medial facet. The epidural contrast layer provides a depth guide deep to which the instrument should not pass; (C) insertion of L5 pedicle screw after completion of S1 screw placement; (D) passage of rod through S1 skin and fascial slit. At this point, most of the epidural contrast has dissipated; (E) decortication of facet surface and preparation of fusion bed through the use of a curette with a sharpened tip.

fusion using mild sedation and local anesthesia, a strategy which obviates the need for general anesthesia and large incisions. All procedures were performed in a biplanar neuroangiographic suite, which allowed for consistent highquality imaging. Such a strategy expands upon the realm of minimally invasive spinal surgery, including percutaneous deformity correction and fracture stabilization.

\section{Methods}

A retrospective review of every patient treated with this protocol was performed after approval of the local Institutional Review Board, and informed consent was obtained from each subject. Adult late middle aged to elderly patients with neuroimaging characteristics and a clinical exam consistent with neurogenic claudication due to focal spinal canal stenosis or discrete foraminal stenosis, combined with significant facet arthropathy and/or coexistent scoliosis were offered the combined procedure. All cases were performed in a biplanar neuroangiographic suite. After administration of a prophylactic antibiotic (1 gram either cefazolin or vancomycin), the patient was positioned prone and mildly sedated with intravenous midazolam and morphine sulfate. Local anesthesia in the lumbar skin, muscles and periosteum was achieved with a combination of $1 \%$ lidocaine and $0.5 \%$ bupivicaine. The pathologic target level was decompressed using a previously described percutaneous method of remodeling and resecting the ligamentum flavum and lamina (mild technique; Vertos Medical, Aliso Viejo, CA, USA) (4-6). In the mild technique, a $6 \mathrm{~mm}$ access cannula is percutaneously inserted via a $10 \mathrm{~mm}$ slit incision and using fluoroscopic control into the interlaminar region (Figure 1). One slit incision is required for each side of a target level. A set of singleuse tools designed for working within the access cannula is then used to resect hypertrophic ligamentum flavum (tissue sculptor) and laminar/medial facet bone (bone sculptor, akin to a Kerrison rongeur). This portion of the procedure is performed under epidurographic control so as to clearly delineate the dural-epidural boundary and diminish the risk of unintentional durotomy. Bone fragments that were harvested from the lamina and medial facet involved with the stenotic segment during the decompression were saved for use in the fusion construct. Once the decompression 


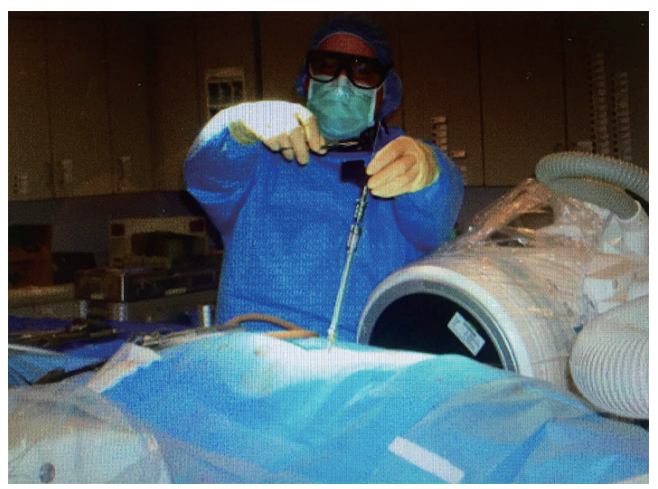

Figure 2 Insertion of pedicle screw over $\mathrm{K}$ wire. At this phase of the case, the anterior-posterior ("A" plane) fluoroscopic tube has been parked cephalad and out of the field so as to allow sufficient working room for the instrumentation and operator's hands. The lateral (" $\mathrm{B}$ " plane) fluoroscopic tube is seen in the working position, providing real-time high-resolution imaging.

had been completed, unilateral pedicle screw fixation was then achieved using commercially available percutaneous pedicle screw fixation techniques (Stryker, Allendale, NJ, USA; Biomet Spine, Parsippany, NJ, USA; Figure 2). If necessary, reduction of malalignment or scoliosis was gently attempted. Bone adjacent to the instrumentation on the facet and laminar surfaces was decorticated with a curette, and then the fusion construct was laid down lateral to the instrumentation. The fusion construct was composed of the laminar bone fragments, which were embedded into a bonemarrow aspirate-soaked allograft-derived demineralized bone matrix sponge (Osteosponge, Bacterin International Holdings, Belgrade, MT, USA) and demineralized bone matrix (Osteoputty, Bacterin International Holdings). The sponge, which acts as a malleable carrier as well as osteobiologic, is then inserted digitally onto the facet region through the pedicle screw access path, taking care to place the autograft bone fragments between the facet surface and the sponge. Skin incisions were closed in a single layer with 3-0 polyglycolic acid suture (Vicryl Rapide, Ethicon, Cincinnati, OH, USA). Patients were allowed to recover for 2-4 hours, then ambulated and discharged to home within 23 hours.

\section{Results}

Thirteen patients were treated, and 3 were male (Table 1). The average age was 74 years (range, 58-87 years). Pathology included grade 1 spondylolisthesis, scoliosis, compression fracture, and facet instability, all of which were combined with stenosis. Levels treated ranged from L1 to L5 for mild decompression targets, and T10 to L5 for pedicle screw instrumentation and fusion (range of stabilization from 2 to 5 segments; Figure 3). The range of medications used during the procedure was as follows: midazolam, 2-4 mg; morphine sulfate, $5-8 \mathrm{mg} ; 1 \%$ lidocaine, $10-47 \mathrm{~mL} ; 0.5 \%$ bupivicaine, $10-30 \mathrm{~mL}$. All patients were easily arousable and cooperative throughout the procedure, and no procedure was aborted due to excessive movement or discomfort. Estimated blood loss ranged from 20-50 mL. Procedural time ranged from 108 to 197 minutes (average 153 minutes).

At first post-operative evaluation (mean 2 weeks, range 1 to 4 weeks), VAS scores for axial spine pain were reduced from a preoperative mean of 7.827 to a postoperative mean of 4.000 ( $\mathrm{P}<0.001$; paired $t$-test, two tailed). Pain reduction was sustained when re-evaluated at the longest postoperative evaluation point, which was a mean of 40 weeks, and a range of 2 to 108 weeks. At this timepoint, the average VAS score for pain was 2.192, which represents a reduction of $5.6(\mathrm{P}<0.00001$; paired $t$-test, two tailed). Of note, 5 patients at longest follow-up were still taking narcotic pain medications, whereas the remaining were not.

No significant complications were observed during the postoperative observation period, including wound infection, cerebrospinal fluid leak, need for blood transfusion, instrumentation failure, deep venous thrombosis, postoperative myocardial infarction, or postoperative new neurologic deficit.

\section{Discussion}

This observational study of 13 patients treated with discrete segmental posterior internal fixation and fusion showed a statistically significant improvement in pain control. Most notably, all procedures were achieved using only local anesthesia and mild sedation, thereby avoiding the potential physiologic disturbances and risks of general anesthesia. Such a strategy has gained attention recently as the advantages of avoiding general anesthesia have become more appreciated $(7,8)$. In addition, the exclusive utilization of slit incisions and image-guided percutaneous techniques markedly limited the amount of tissue dissection and blood loss $(9,10)$. Such approaches allow a patient population traditionally neglected to undergo treatment for painful spinal conditions (11-13).

The primary endpoints in this study were safety and 


\begin{tabular}{|c|c|c|c|c|c|c|c|c|c|c|}
\hline \multirow{2}{*}{ ID } & \multirow{2}{*}{ Age } & \multirow{2}{*}{ Sex } & \multicolumn{3}{|l|}{ VAS } & \multicolumn{2}{|c|}{$\begin{array}{l}\text { Follow-up } \\
\text { interval (weeks) }\end{array}$} & \multirow{2}{*}{ Narcotics } & \multirow{2}{*}{ Patient history } & \multirow{2}{*}{ Procedure } \\
\hline & & & $\begin{array}{l}\text { Pre- } \\
\text { Op }\end{array}$ & $\begin{array}{l}\text { Post- } \\
\text { Op } 1\end{array}$ & $\begin{array}{l}\text { Post- } \\
\text { Op } 2\end{array}$ & $\begin{array}{l}\text { Post- } \\
\text { Op } 1\end{array}$ & $\begin{array}{l}\text { Post- } \\
\text { Op } 2\end{array}$ & & & \\
\hline 1 & 83 & M & 6 & 1 & 0 & 2 & 52 & No & $\begin{array}{l}\text { T11 chronic fx, L1-L2 stenosis, } \\
1 \text { year s/p MVA }\end{array}$ & $\begin{array}{l}\text { Left T10-L2 pedicle screw fixation/ } \\
\text { fusion, L1-L2 mild }\end{array}$ \\
\hline 2 & 68 & $\mathrm{~F}$ & 6 & 5 & 1.5 & 1.5 & 54 & Yes & $\begin{array}{l}\text { L4-L5 stenosis, facet } \\
\text { arthropathy }\end{array}$ & $\begin{array}{l}\text { Bilateral L4-L5 mild, left L4-L5 } \\
\text { pedicle screw instrumentation/fusion }\end{array}$ \\
\hline 3 & 87 & $\mathrm{~F}$ & 7 & 5 & 3.5 & 1.5 & 14 & Yes & $\begin{array}{l}\text { L4-L5 stenosis, spondylosis, } \\
\text { facet arthropathy }\end{array}$ & $\begin{array}{l}\text { Left L4-L5 mild, right L4-L5 pedicle } \\
\text { screw instrumentation/fusion }\end{array}$ \\
\hline 4 & 72 & M & 8 & 0 & 1.5 & 3 & 80 & No & $\begin{array}{l}\text { L3-L4 stenosis, L4-L5 facet } \\
\text { arthropathy }\end{array}$ & $\begin{array}{l}\text { Left L3-L4 mild, Left L4-L5 pedicle } \\
\text { screw instrumentation }\end{array}$ \\
\hline 5 & 94 & M & 6.5 & 1 & 3 & 1.5 & 60 & No & Left L3-L4 facet arthropathy & $\begin{array}{l}\text { Left L3-L4 mild, Left L3-L4 pedicle } \\
\text { screw instrumentation/fusion }\end{array}$ \\
\hline 6 & 79 & M & 9 & 9 & 9 & 4 & 72 & Yes & $\begin{array}{l}\text { L3-L5 Stenosis and facet } \\
\text { arthropathy }\end{array}$ & $\begin{array}{l}\text { Right L3-L4 mild and right pedicle } \\
\text { screw instrumentation/fusion, left } \\
\text { L4-L5 mild and left pedicle screw } \\
\text { instrumentation/fusion }\end{array}$ \\
\hline 7 & 77 & $\mathrm{~F}$ & 6.25 & 1 & 0 & 1.5 & 108 & No & $\begin{array}{l}\text { L3-L4 spondylolisthesis and } \\
\text { L3-L4 stenosis }\end{array}$ & $\begin{array}{l}\text { Left L3-L4 mild and left L3-L4 pedicle } \\
\text { screw instrumentation/fixation }\end{array}$ \\
\hline 8 & 81 & $\mathrm{~F}$ & 7 & 0 & 0 & 3 & 12 & Yes & $\begin{array}{l}\text { L1 chronic compression } \\
\text { fracture and kyphosis }\end{array}$ & $\begin{array}{l}\text { Right T12-L2 pedicle screw } \\
\text { instrumentation/fusion }\end{array}$ \\
\hline 9 & 57 & $\mathrm{~F}$ & 9 & 4 & 4 & 2 & 18 & No & $\begin{array}{l}\text { L2-L3 stenosis with facet } \\
\text { arthropathy }\end{array}$ & $\begin{array}{l}\text { Left L2-L3 mild and Left L2-L3 } \\
\text { pedicle screw instrumentation/fusion }\end{array}$ \\
\hline 10 & 54 & $\mathrm{~F}$ & 10 & 5 & 0 & 3 & 12 & No & $\begin{array}{l}\text { congenital scoliosis w/ L3 } \\
\text { fusion mass fracture, existing } \\
\text { Harrington rod construct }\end{array}$ & $\begin{array}{l}\text { Left L1-L4 pedicle screw } \\
\text { instrumentation/fusion }\end{array}$ \\
\hline 11 & 77 & M & 8 & 7 & 2 & 1 & 26 & No & $\begin{array}{l}\text { L3-L4 stenosis, chronic L5 pars } \\
\text { defect and spondylolithesis }\end{array}$ & $\begin{array}{l}\text { Bilateral L3-L4 mild, right L5-S1 } \\
\text { pedicle screw instrumentation/fusion }\end{array}$ \\
\hline 12 & 79 & $\mathrm{~F}$ & 9 & 6 & 4 & 1 & 2 & Yes & $\begin{array}{l}\text { stenosis and facet arthropathy } \\
\text { L3-L5 }\end{array}$ & $\begin{array}{l}\text { Bilateral L3-L4 mild, right L3-L4-L5 } \\
\text { pedicle screw instrumentation/fusion }\end{array}$ \\
\hline 13 & 66 & $\mathrm{~F}$ & 10 & 8 & 0 & 1.5 & 12 & No & Left T10-T11 foraminal stenosis & $\begin{array}{l}\text { Left T10-T11 pedicle screw } \\
\text { instrumentation/fusion }\end{array}$ \\
\hline
\end{tabular}
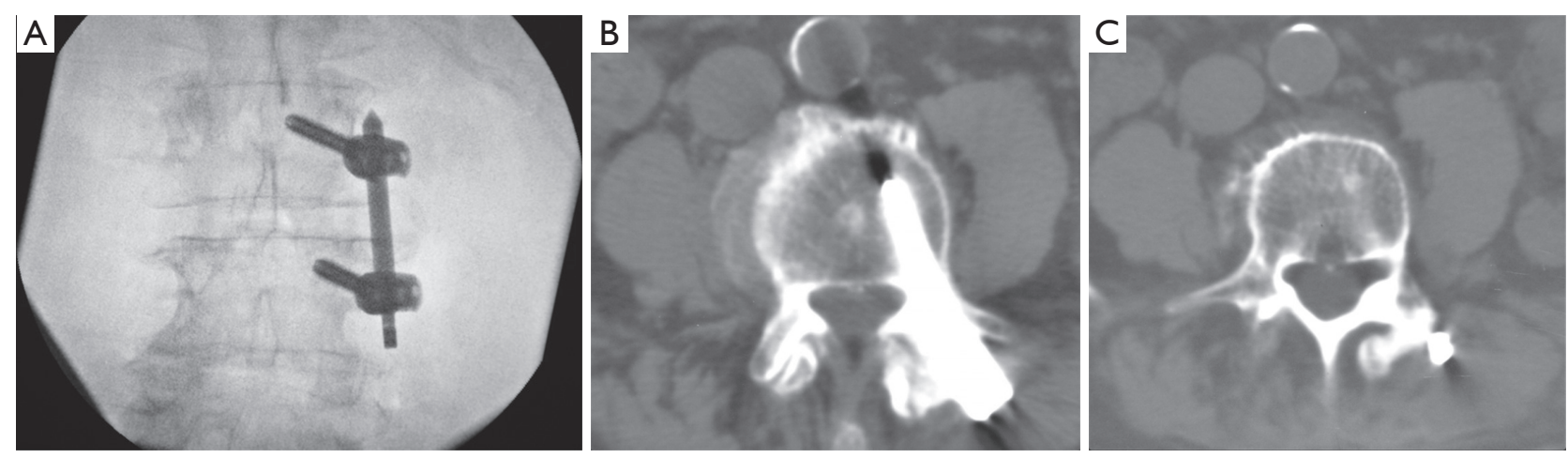

Figure 3 Images from case 5, a 94-year-old male who underwent left L3-L4 mild decompression and pedicle screw fusion. (A) Final construct image from the biplane angiographic suite; (B) axial CT image at L4 level obtained 14 months after procedure. Note solid fusion mass medial to screw head; (C) axial CT image at L3 level, demonstrating fusion mass medial to instrumentation. 
overall pain relief. While it stands to reason that a successful fusion construct is associated with durable pain relief, other mechanisms such as the presence of a rigid segmental fixation device may also play a role. Except in a minority of patients, post-operative imaging of the fusion construct was not routinely obtained, and therefore no conclusion can be reached as to the success rate of this particular technique with respect specifically to the achievement of solid bony fusion. A future study design should include long-term imaging studies as well as a more detailed evaluation of post-operative functional status, such as the Oswestry Disability Scale.

Insertion of spinal instrumentation into the awake, sedated patient requires a heightened sensitivity to patient needs and situational awareness. A major key to success rests with the preoperative discussion, where the surgeon needs to carefully paint an accurate portrayal of the surgery, including the sights and sounds inherent to the procedure. For instance, it is helpful if the patient is forewarned as to the expected squeal of a blocker cap during final torque application, or the gentle tap of a mallet against a bone biopsy needle. Carefully and vividly previewing the procedure with the patient will greatly diminish anxiety and minimize unanticipated movements.

Spinal instrumentation procedures carry with them a number of specific risks, not the least of which is infectious complications. Expanding such procedures into a non-traditional operating room setting requires sensitivity towards the inherent cultural differences between angiography suites and operating theaters. In the current study, great effort was spent in the training of radiology technologists as to scrupulous sterile technique. In addition, traffic control was a major concern, as many angiography suites tolerate ingress and egress of personnel at a high frequency, including individuals wearing "street clothes". If this strategy is to be applied on a wider basis, then education as to appropriate sterile technique within and around the angiography suite and associated control room will be essential in order to protect patients from surgical site infections. The appeal of the biplane suite as an alternative "hybrid" or even first choice site for neurosurgical procedures has been growing, and reports of novel suite utilization will likely continue to grow (14).

Obvious limitations surround this pilot study including small sample size, the inherent bias of a retrospective case series, and heterogeneous pathology. In addition, the economic cost of this strategy warrants discussion, as it could be argued that the application of these techniques represents an overly aggressive approach to the aged spine. Certainly, debates surrounding cost and application of medical device technology will only become more prevalent as the population ages, and the pool of potential patients increases.

\section{Acknowledgements}

None.

\section{Footnote}

Conflicts of Interest: Dr. Chopko is a consultant as well as a member of the Scientific Advisory Board for Vertos Medical, and has received compensation in the form of consulting fees and stock option grants. During the time of data collection, Dr. Chopko was a consultant for Bacterin International Holdings, where he received compensation in the form of consulting fees, and was also a member of the Scientific Advisory Board.

Ethical Statements: Under the local institutional review board (IRB) approval for this study, the research study is referenced by name only ("Percutaneous thoracolumbar decompression and pedicle screw instrumentation/fusion using local anesthesia and mild sedation: retrospective review of data") and a number was not assigned. The study approval was issued under "Federalwide Assurance (FWA) \#00004606.”

\section{References}

1. Kim CW, Siemionow K, Anderson DG, et al. The current state of minimally invasive spine surgery. J Bone Joint Surg Am 2011;93:582-96.

2. Dong J, Rong L, Feng F, et al. Unilateral pedicle screw fixation through a tubular retractor via the Wiltse approach compared with conventional bilateral pedicle screw fixation for single-segment degenerative lumbar instability: a prospective randomized study. J Neurosurg Spine 2014;20:53-9.

3. Mohr M, Pillich D, Kirsch M, et al. Percutaneous balloon kyphoplasty with the patient under intravenous analgesia and sedation: a feasibility study. AJNR Am J Neuroradiol 2011;32:649-53.

4. Chopko BW. A novel method for treatment of lumbar spinal stenosis in high-risk surgical candidates: pilot study 
experience with percutaneous remodeling of ligamentum flavum and lamina. J Neurosurg Spine 2011;14:46-50.

5. Schomer DF, Solsberg D, Wong W, et al. mild(®) Lumbar Decompression for the Treatment of Lumbar Spinal Stenosis. Neuroradiol J 2011;24:620-6.

6. Benyamin RM, Staats PS1, MiDAS Encore I. MILD® Is an Effective Treatment for Lumbar Spinal Stenosis with Neurogenic Claudication: MiDAS ENCORE Randomized Controlled Trial. Pain Physician 2016;19:229-42.

7. Ahn Y, Oh HK, Kim H, et al. Percutaneous endoscopic lumbar foraminotomy: an advanced surgical technique and clinical outcomes. Neurosurgery 2014;75:124-33; discussion 132-3.

8. Telfeian AE, Choi DB, Aghion DM. Transforaminal endoscopic surgery under local analgesia for ventral epidural thoracic spinal tumor: Case report. Clin Neurol Neurosurg 2015;134:1-3.

9. Shousha M, Cirovic D, Boehm H. Infection rate after minimally invasive noninstrumented spinal surgery based on 4350 procedures. Spine (Phila Pa 1976) 2015;40:201-5.
10. Liu Z, Fei Q, Wang B, et al. A meta-analysis of unilateral versus bilateral pedicle screw fixation in minimally invasive lumbar interbody fusion. PLoS One 2014;9:e111979.

11. Khashan M, Lidar Z, Salame K, et al. Minimally Invasive Spinal Decompression in Patients Older Than 75 Years of Age: Perioperative Risks, Complications, and Clinical Outcomes Compared with Patients Younger Than 45 Years of Age. World Neurosurg 2016;89:337-42.

12. Gu YT, Zhu DH, Liu HF, et al. Minimally invasive pedicle screw fixation combined with percutaneous vertebroplasty for preventing secondary fracture after vertebroplasty. J Orthop Surg Res 2015;10:31.

13. Kwan MK, Lee CK, Chan CY. Minimally Invasive Spinal Stabilization Using Fluoroscopic-Guided Percutaneous Screws as a Form of Palliative Surgery in Patients with Spinal Metastasis. Asian Spine J 2016;10:99-110.

14. Rose KR, Stone JJ, Ren Z, et al. Percutaneous trigeminal rhizotomy in a biplane angiosuite: technical assessment. J Neurointerv Surg 2014;6:699-703.
Cite this article as: Chopko BW. Percutaneous thoracolumbar decompression combined with percutaneous pedicle screw fixation and fusion: a method for treating spinal degenerative pain in a biplane angiography suite with the avoidance of general anesthesia. J Spine Surg 2016;2(2):122-127. doi: 10.21037 /jss.2016.06.03 